\title{
UNIVERSIDADE CORPORATIVA DESENVOLVE COMPETÊNCIAS PARA O TRABALHO? O PONTO DE VISTA DOS PROFISSIONAIS
}

\section{CORPORATE UNIVERSITY DEVELOPS COMPETENCES FOR WORK? THE POINT OF VIEW OF PROFESSIONALS}

Patrícia Oliveira Nascimento

Mestre em Administração pela Universidade Federal do Espírito Santo

Vitória, ES, Brasil

E-mail: patricia_on@hotmail.com

Mônica de Fátima Bianco

Professora na Universidade Federal do Espírito Santo

Vitória, ES, Brasil

E-mail: mofbianco@gmail.com

\section{RESUMO}

Este artigo objetiva descrever o Programa de Desenvolvimento de Lideranças, oferecido pela Universidade Corporativa de uma empresa mineradora de grande porte, com atuação na região sudeste do Brasil, e compreender as possíveis relações deste Programa com o desenvolvimento das competências sob o ponto de vista dos profissionais e esperado pela Organização. A Universidade Corporativa desta empresa foi criada em 2003, sob o propósito de transformar vidas desenvolvendo pessoas, e é vista como fator de importância para a geração de competitividade, evolução nos negócios e aumento da sinergia organizacional. Para esta pesquisa, de natureza qualitativa, foram entrevistados quatro profissionais voluntários, Supervisores da mineradora, que tiveram a oportunidade de participar de seu Programa de Desenvolvimento de Lideranças. Realizaram-se entrevistas semi-estruturadas e pesquisa documental para obtenção de dados, em 2014. Optou-se pela Análise de Conteúdo como método de análise. Para a empresa estudada, o Programa de Desenvolvimento de Lideranças é importante ferramenta para o desenvolvimento das competências esperadas pela organização, sendo reconhecida pelos profissionais pelo conhecimento técnico gerencial que oferece e pela troca de experiências que promove entre os profissionais, garantindo-lhes melhoria na prática gerencial cotidiana. Contudo, não se trata da principal ferramenta, estando nítido que este desenvolvimento vai muito além dos Programas oferecidos por sua Universidade Corporativa.

Palavras-chave: Competência. Universidade Corporativa. Gestão e Liderança. Mineração.

\section{ABSTRACT}

This article aims to describe the Leadership Development Program, offered by the Corporate University of mining company with operations in Vitoria / ES, and understand the possible relationship of this program to the development of professional competencies expected by the Organization. The Corporate University this mining company was created in 2003, under the purpose of transforming lives by developing people, and is seen as extremely important factor for the generation of competitiveness, business development and increased organizational synergy. For conducting this qualitative research, were interviewed four Supervisors miner, who had the opportunity to participate in its Leadership Development Program. Semi-structured interviews and document research were conducted to obtain data. It is chosen for content analysis as a method of analysis. For the studied company, the Leadership Development Program is an important tool for the development of the expected competencies for the organization, and is recognized by both the professional managerial expertise and by providing exchange of experiences among professionals that promotes, guaranteeing them improved everyday managerial practice. However, it is not the primary tool, being clear that this development goes beyond the programs offered by their Corporate University.

Keywords: Competence. Corporate University. Management and Leadership. Mining.

Data de aprovação: 02 de maio de 2017.

Data de submissão: 29 de outubro de 2014. 


\section{INTRODUÇÃO}

O "mundo" do trabalho não é estático, uma constatação direta e simples. O tempo e a história perpassam o Trabalho e as Organizações, conduzindo-os a mudanças, seja no ato de produzir, seja nas interações que a partir destes são construídas.

O dinamismo que advém das práticas laborais é notado antes mesmo das chamadas Teorias Clássicas da Administração. Pode-se afirmar que, desde a organização do trabalho na sociedade feudal, seguido da organização do trabalho pela produção artesanal, da Revolução Industrial, das Teorias Clássicas da Administração representadas pelo taylorismo-fordismo, da crise os modos de produção e alcançando o modo de produção flexível (SALERNO, 1999) e a gestão participativa (FARIA, 2009), estática faz-se uma palavra desconhecida para os estudos do trabalho e organizacionais.

Se na organização do trabalho feudal tínhamos como centro os proprietários de terra e uma economia patrimonial regida pela lealdade e dependência (WEBER, 1982), destaca-se hoje uma organização com processos flexíveis, atenta às tecnologias da informação e à otimização de sua produção, relacionando-se em redes (CASTELLS, 1999). Se antes tínhamos o artesão como dono de sua força de trabalho, hoje se busca o exercício da competência (ZARIFIAN, 2001; 2003; BOLTANSKI \& CHIAPELLO, 2009).

Em breve reflexão sobre mudanças na organização do trabalho e das organizações, a partir da Teoria Clássica da Administração, vê-se a dissociação entre o planejamento e a execução do taylorismo, em um adestramento de sua força de trabalho - o trabalhador (FARIA, 2008), a massificação da produção e do consumo no ritmo das esteiras industriais de Henry Ford (BRAVERMAN, 1974; HARVEY, 1992) e as mudanças do mundo pós-guerra, que migra os mercados produtivos para regiões menos desenvolvidas, com mão de obra mais barata e leis flexíveis (HARVEY, 1992; CASTELLS, 1999) e o surgimento de novos modos de gestão do trabalho, como just-in-time via kanban, por exemplo. A capacidade de transformar conhecimento tácito em explícito, a comunicação e a informação são consideradas aspectos-chave pertinentes ao mundo do trabalho (TAKEUCHI E NONAKA, 2008) e novas moedas a serem capitalizadas.

Tais mudanças na organização do trabalho acarretam também mudanças nas exigências ao profissional, que agora não mais executa uma única tarefa na linha de produção e precisa ser capaz de diversificar suas atividades e colaborar para o desempenho do grupo, desenvolvendo, então, novas competências. Este novo cenário laboral compreende uma maior complexidade em suas relações com o ambiente, que se configura em uma grande rede, cada vez mais integrado, dinâmico e global, e exige mais do trabalhador, que agora é estimulado e exigido a ter ações de reflexão, planejamento, execução e avaliação, além da capacidade de lidar com a diversidade de situações e eventos que permeiam sua rotina (CASTELLS, 1999). Neste sentido, o trabalhador reveste-se de uma competência profissional (LE BOTERF, 2003), contingente, que, na situação de trabalho, extrai deste sujeito todos os seus recursos disponíveis para a melhor realização da atividade.

Diante do valor atribuído ao conhecimento, das competências requeridas ao trabalhador e do dinamismo imposto pelas redes que se configuram, o trabalhador passa a ser integrante fundamental do processo produtivo e importante fator de sucesso para as organizações. A gestão de pessoas ganha status estratégico para as organizações, destacando-se como fator crítico o desenvolvimento e a formação de profissionais competentes (ALPERSTEDT, 2001). Para Eboli (2004, p. 41) "é absolutamente necessário que 
as empresas desenvolvam seus talentos e competências a fim de aumentar sua competitividade e obter melhores resultados nos negócios".

Como alternativa às organizações para a formação e retenção de profissionais competentes, surgem então os Programas de Educação Corporativa que, para este artigo, será sinônimo de Universidade Corporativa. Eboli (2004) destaca que a postura voltada para a aprendizagem contínua, para o autodesenvolvimento e para a formação de competências deve estar presente nas práticas do individuo, mas que "cabe às organizações, entretanto, criar um ambiente favorável para sua manifestação" (EBOLI, 2004, p. 44).

Atentas a esse diferencial competitivo, as empresas seguem investindo valores monetários na composição e na manutenção das Universidades Corporativas. Segundo pesquisa da Associação Brasileira de Treinamento e Desenvolvimento - ABTD, nos anos de 2013-2014, identifica-se que $11 \%$ das empresas possuem Universidade Corporativa e que, para empresas acima de 50 mil funcionários, este percentual elevase para $23 \%$.

Avançando nos estudos em universidade corporativa, este trabalho busca compreender a percepção da formação de competências desejadas pelas organizações sob o ponto de vista dos profissionais, a partir dos programas oferecidos pela Universidade Corporativa, bem como discutir a efetividade das práticas da Universidade Corporativa, aspecto que, segundo BRANDÃO (2006), considera-se uma lacuna nos estudos deste tema, o que o levantamento bibliográfico realizado em periódicos da área - RAC (Revista de Administração Contemporânea), RAE (Revista de Administração de Empresas), Revista de Administração (São Paulo), Psicologia: Reflexão e Crítica, Organizações \& Sociedade - confirmou. Trata-se de uma pesquisa qualitativa, realizada em empresa mineradora líder de mercado mundial em produção de minério de ferro, com representativa atuação no mercado global, doravante denominada Empresa Gama. O artigo estrutura-se em três partes, além desta introdução. Na primeira parte, apresentam-se os conceitos de competência e de educação corporativa. Na segunda parte, são expostos os aspectos metodológicos da pesquisa, assim como os seus resultados. A última parte está dedicada às considerações finais.

\section{COMPETÊNCIAS E EDUCAÇÃO CORPORATIVA}

Abordar-se-ão os conceitos de Competências e de Educação Corporativa, realizando um breve contexto histórico e buscando iniciar a compreensão da relação entre estas duas temáticas. Para tanto, é importante apropriar-se da diferenciação feita por Zarifian (2003) entre qualificação e competência: a primeira relacionando-se aos recursos adquiridos pelo individuo, seja por sua formação, seja por sua experiência prática e/ou vivência profissional, e a segunda relacionando-se à capacidade de utilizar estes recursos na prática.

Para Zarifian (2003), o modelo de competência conta com o contexto histórico como aliado para sua emergência, que se destaca a partir da década de 1970, quando os critérios de autonomia e responsabilidade compõem os requisitos do emprego e marcam uma inversão de valores em relação ao taylorismo. Ou seja, há a valorização da autonomia do indivíduo em detrimento das regras a serem seguidas, o que reforça questões referentes à individualidade e à demarcação de papéis e funções dentro das organizações e equipes de trabalho: quanto mais qualificado, maior a autonomia que o empregado possibilitará. 
A proximidade do profissionalismo às competências é enfatizada por Le Boterf (2003), sendo esse reconhecido por uma combinação singular destas. Sob esta ótica, há uma valorização das ações esperadas diante do contexto organizacional específico: não só a capacidade de mobilizar recursos próprios está em questão, mas também a capacidade de contextualizar e apropriar-se de recursos disponibilizados pelo ambiente e pelas contingências. A competência é, então, sempre "competência para", e o profissional competente é aquele que é capaz de agir com competência, ou seja, aquele que sabe interpretar, que sabe o que fazer diante das demandas organizacionais. A competência se realiza na ação. Os resultados obtidos demarcam sua existência ou não, que é, vale frisar, sempre contingente. Ou seja: a competência profissional se realiza na ação, não podendo ser preexistente a ela.

Dutra (2010) associa a questão das competências ao conceito de entrega, ou seja, a avaliação da capacidade de entrega do indivíduo, entendendo-se por entrega os resultados, as ações, as realizações e a forma de atuação do sujeito dentro das organizações. Para Fleury e Fleury (2001), considerando os aspectos sociais envolvidos, competência é "um saber agir responsável e reconhecido, que implica mobilizar, integrar, transferir conhecimentos, recursos e habilidades, que agreguem valor econômico à organização e valor social ao indivíduo".

Agregar valor econômico e social é uma busca constante das organizações no mercado competitivo e acirrado da atualidade. A formação deste profissional, capaz de lidar com todas as variações e mudanças de um mercado estruturado em redes, eleva os processos e rotinas de gestão de pessoas à estratégia da organização, dando-Ihe maior destaque e visibilidade.

Visando esta formação, Zarifian (2003) enfatiza a importância da aliança entre a qualificação e a formação contínua pela prática, entendendo que deve haver um equilíbrio entre a educação formal e as práticas laborais. Para Le Boterf (2003), a formação da competência é resultante da convergência de se saber agir, querer agir e poder agir. Para este autor, a "responsabilidade da construção das competências é uma responsabilidade compartilhada. Três tipos de atores estão particularmente envolvidos nisso: o indivíduo, o gestor e o formador/gerenciador dos recursos humanos" (LE BOTERF, 2003, p. 161, grifo do autor).

Considerando isso, as empresas voltam-se para ferramentas que possam proporcionar tal desenvolvimento, e estruturam-se as áreas de treinamento, desenvolvimento e, posteriormente, educação corporativa.

Inicialmente, as áreas de Treinamento e Desenvolvimento, T\&D, estavam habituadas a "entregar cursos ao público interno por força de demandas concretas, oferecendo programa cujo objetivo principal era desenvolver habilidades específicas que enfatizassem necessidades individuais e sempre de um escopo estratégico" (EBOLI, 2002, p.187, grifo da autora).

Em um avanço conceitual, o termo Educação associa-se a expressão Treinamento e Desenvolvimento, que agora passa a ser Treinamento, Desenvolvimento e Educação (TD\&E). Entende-se então que permanece o conceito de Treinamento, associado ao desempenho e às oportunidades de aprendizagem promovidas pelas organizações aos seus funcionários para superação de lacunas, preparação para novos cargos e uso de novas tecnologias, bem como o conceito de Desenvolvimento, como estímulo ao profissional para buscar seu próprio crescimento pessoal, não estando necessariamente vinculado ao desempenho, e associa-se a expressão Educação, ressaltando uma preparação para a vida, não sendo, portanto, responsabilidade das organizações (PILATI; VASCONCELOS; BORGES-ANDRADE, 2011). 
Contudo, como já pontuado por Zarifian (2001; 2003), a simples capacitação, ou entrega de cursos, deslocada da prática e vivência laboral, muito pouco ou em nada contribuem para a formação de competências. $E$ as organizações, percebendo esta limitação e atentas às suas novas demandas, ampliam o escopo de suas ações de TD\&E. E, neste escopo, uma nova denominação surge: as Universidades Corporativas (UC). Jeanne Meister define UC como:

Um guarda-chuva estratégico para o desenvolvimento e a educação de funcionários, clientes e fornecedores, buscando otimizar as estratégias organizacionais, além de um laboratório de aprendizagem para a organização de um pólo permanente (MEISTER, 1999, p. 8)

Para Meister (1999), a utilização do termo Universidade confere a credibilidade e visibilidade às "novas" áreas de T\&D, mesmo não tendo contemplado em suas práticas atividades características de uma Universidade, como pesquisa e extensão, por exemplo. A utilização deste termo torna-se um diferencial mercadológico.

Alinhada às práticas educacionais norte-americanas, esta autora defende a aproximação entre universidades e organizações. Esta aproximação deve ter por objetivo adequar o ensino às necessidades e realidades das organizações e do mercado, o que abre espaço para a interferência direta das organizações nas práticas educacionais.

Eboli (1999) traz como missão da Universidade Corporativa a formação e desenvolvimento de "talentos humanos na gestão de negócios, promovendo a gestão do conhecimento organizacional (geração, assimilação, difusão e aplicação), através de um processo de aprendizagem ativa e contínua" (EBOLI, 1999, p. 59). Para esta autora, as UC's têm como objetivo principal desenvolver e instalar competências profissionais, técnicas e gerenciais que sejam essenciais para o alcance das estratégias do negócio (EBOLI, 1999).

Eboli (1999) acena para diferenças de perspectivas ao se tratar de UC's, visto que a visão de desenvolvimento não mais se associa principalmente ao indivíduo, e sim a cultura e objetivos organizacionais. Desta forma, as ações de educação corporativa deixam de ter como foco o treinamento e desenvolvimento do indivíduo e priorizam o desenvolvimento de competências vinculadas à estratégia da organização. Tais mudanças de paradigma, trazidas por Eboli (1999), podem ser vistas na Figura 1.

Figura 1 - Mudança de Paradigma Centro de T\&D para Universidade Corporativa

\begin{tabular}{|lcl|}
\multicolumn{2}{c}{ Mudança de Paradigma } \\
Centro de Treinamento Tradicional & $\rightarrow$ & Universidade Corporativa \\
\hline Desenvolver habilidades & Objetivo & Desenvolver competências críticas \\
Aprendizado individual & Foco & Aprendizado organizacional \\
Tático & Escopo & Estratégico \\
Necessidades individuais & Ênfase & Estratégias de negócios \\
Interno & Público & Interno e externo \\
Espaço real & Local & Espaços real e virtual \\
Aumento das habilidades & Resultado & Aumento do desempenho \\
\hline
\end{tabular}

Fonte: Eboli (1999); adaptado de Meister (1998) 
Vale ressaltar que, assim como Eboli (2002), os termos Universidade e Educação Corporativa serão aqui utilizados livremente como equivalentes, visto que "na prática, é a universidade corporativa que traz à tona a nova modalidade de educação corporativa" (EBOLI, 2002, p. 192). E esta nova modalidade de educação corporativa colabora com a formação de competências?

Infere-se que o conceito de Educação Corporativa se alinha a necessidade já levantada por Zarifian (2001) da aproximação entre a situação escolar e a situação de trabalho, entendendo que ambos têm importante papel na formação das competências do indivíduo. De um lado, a situação escolar deve estar atenta a prática laboral dos conhecimentos adquiridos, vislumbrando a inserção do profissional em situações que Ihe permitam mobilizar seus conhecimentos para a ação. Por outro lado, a situação de trabalho vai além do detalhamento dos afazares dos postos de trabalho, entendendo a referência a seus saberes.

Tal alinhamento se dá por acreditar que as ações em educação corporativa se vinculam a esta aproximação entre o referencial teórico e a prática laboral, voltados para a estratégia organizacional e a formação de competências que as atenda.

Para Eboli (2004), a implantação da Universidade Corporativa deve ter como reflexão três situações distintas, conforme Figura 2. Ou seja, a função estratégica da educação corporativa é reafirmada como fator de competitividade e desenvolvimento organizacional e, para tanto, deve estar sempre alinhada aos objetivos e premissas estratégicas da empresa. Há a crença de que a educação corporativa, por sua abordagem educacional, seja capaz de formar e desenvolver competências essenciais a continuidade e sustentabilidade das organizações.

\section{Figura 2 - Educação Corporativa: articulando conceitos}

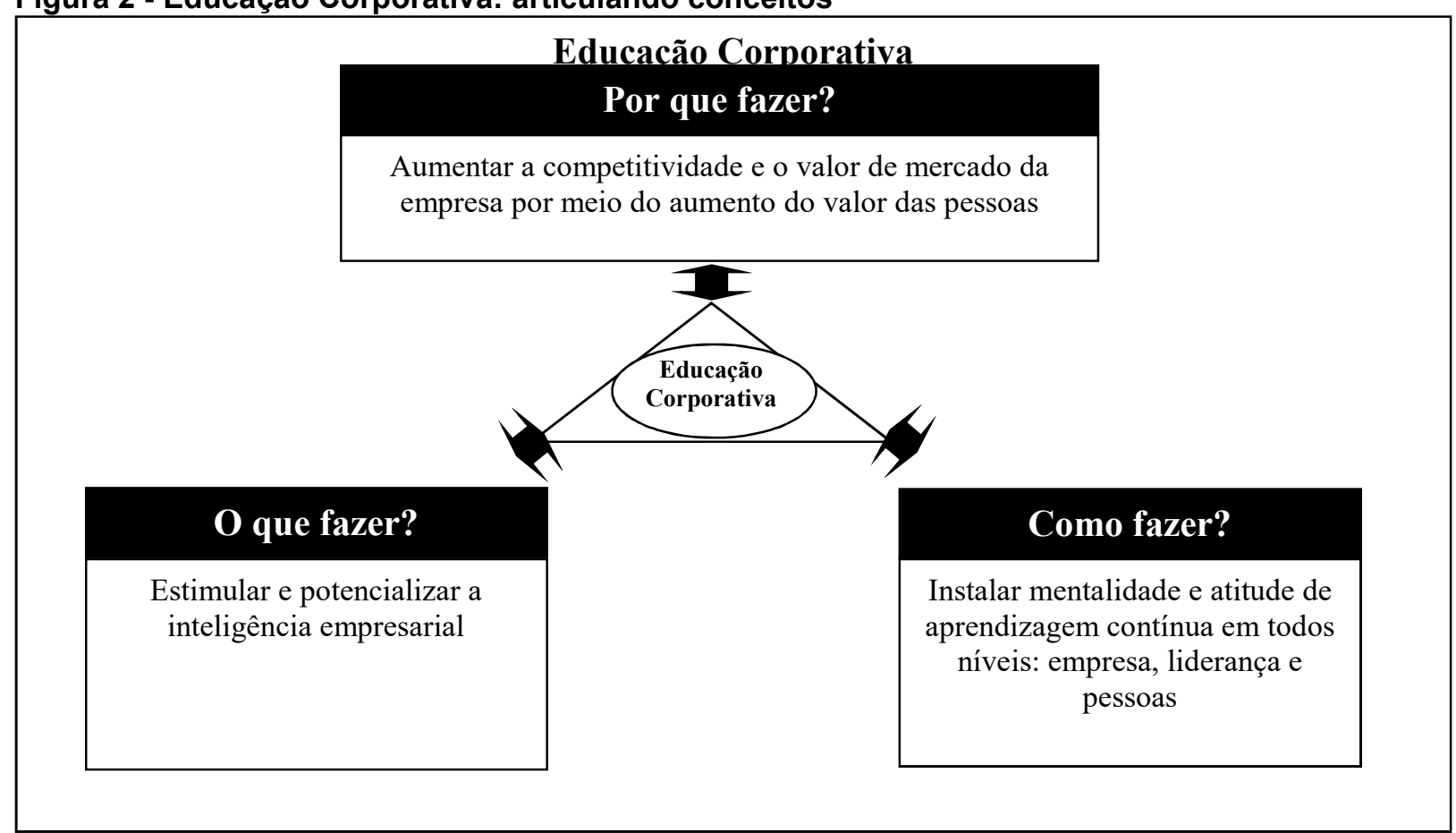

Adaptado de EBOLI, 2004 (p. 53) 
Esta visão, voltada para o mercado, predomina em todos os aspectos - desde a escolha de mercados econômicos a apoio a iniciativas e projetos sociais - na gestão estratégica da Empresa Gama, local em que este trabalho foi desenvolvido. Mas, o questionamento permanece: será mesmo a educação corporativa capaz de desenvolver competências para o trabalho?

\section{ASPECTOS METODOLÓGICOS E RESULTADOS DE PESQUISA}

Esta é uma pesquisa teórico-empírica, de abordagem qualitativa. A escolha por esta abordagem justifica-se pela busca da compreensão do fenômeno em profundidade e, conforme Flick (2004), a pesquisa qualitativa possui relevância para os estudos das relações sociais em um mundo tão plural, trazendo uma nova visão sensibilizada para os problemas empíricos propostos. Segundo Godoy (1995),

(...) a pesquisa qualitativa não procura enumerar e/ou medir os eventos estudados, nem emprega instrumental estatístico na análise de dados. Parte de questões ou focos de interesses amplos, que vão se definindo a medida que o estudo se desenvolve. Envolve a obtenção de dados descritivos sobre pessoas, lugares e processos interativos pelo contato direto do pesquisador com a situação estudada, procurando compreender os fenômenos segundo a perspectiva dos sujeitos, ou seja, dos participantes da situação em estudo (GODOY, 1995, p.58)

Os métodos escolhidos para a obtenção de dados foram a realização de entrevistas semiestruturadas e a análise documental. Considera-se que a análise documental é um importante registro bibliográfico que suportará o conhecimento da realidade da Empresa Gama. Quanto à opção pela entrevista semi-estruturada, Gaskell (2002) indica que

[o] emprego da entrevista qualitativa para mapear e compreender o mundo da vida dos respondentes é o ponto de entrada para o cientista social que introduz, então, esquemas interpretativos para compreender as narrativas de atores em termos conceptuais e abstratos, muitas vezes em relação a outras observações. A entrevista qualitativa, pois, fornece os dados básicos para o desenvolvimento e a compreensão das relações entre os atores sociais e a situação. O objetivo é uma compreensão detalhada das crenças, atitudes, valores e motivações, em relação aos comportamentos das pessoas em contextos sociais específicos. (GASKELL, 2002, p. 65)

Para a análise dos dados, será utilizado o método de Análise de Conteúdo, que toma como sua unidade a mensagem, seja ela oral, corporal escrita e os significados e sentidos que emitem em um determinado contexto (FRANCO, 2003). Bardin (2006) define a análise de conteúdo como "uma técnica de investigação que através de uma objetiva, sistemática e quantitativa do conteúdo manifesto das comunicações, tem por finalidade a interpretação destas mesmas comunicações" (BARDIN, 2006, p. 36). Embora tenha a linguagem como fonte primária de dados, a análise de conteúdo preocupa-se com o que foi explicitado pelo sujeito, não estando em busca de conteúdo 'por de trás' da palavra e nem tão pouco preocupada com aspectos lingüísticos.

O local escolhido foi a Empresa Gama, mineradora sediada no Brasil e com uma de suas unidades na região sudeste do Brasil. Trata-se de uma mineradora global, líder na produção de minério de ferro, destaque nos mercados de fertilizantes, de logística e transporte e de energias. 
Embora a pesquisa tenha acontecido na unidade local, o contato inicial se deu junto à gestão de educação corporativa, responsável por toda inovação e ações educacionais, em nível mundial, da Empresa Gama. Este centro de desenvolvimento de novas tecnologias vivencia e reforça a necessidade do alinhamento estratégico às ações da educação corporativa, concentrando em si as demandas de todas as unidades, promovendo uma visão geral do negócio, a identificação de necessidade semelhantes a toda organização e o desenvolvimento de tecnologias que sejam aplicadas à toda organização, conferindo-lhe perenidade e sustentabilidade.

\section{Resultados}

Voltando-se para a Empresa Gama, esta foi criada em 1942, estatal, em meio à II Grande Guerra, com o objetivo de garantir aos aliados o fornecimento de minério de ferro para suas indústrias. $O$ tempo passa e a Empresa Gama acompanha as mudanças no mercado, investindo em tecnologias de produção e de gestão, incluindo a sua privatização. Em 1942, a produção equivalia a 40 mil toneladas de minério por ano: hoje, esta mesma quantidade é produzida em apenas uma hora.

A Empresa Gama conta com 10.600 empregados nas instalações locais da investigação na região sudeste, que operam quatro terminais portuários usados para movimentar minério de ferro e pelotas, carvão, grãos e fertilizantes e líquidos a granel. Além dos terminais, a Empresa Gama conta com oito usinas de pelotização, sendo 02 de operação totalmente nacional e as demais com operações compartilhadas com empresas da Espanha, Estados Unidos, Japão e Coréia, e também é responsável por parte da operação da ferrovia Vitória-Minas.

Em 2003, sob o propósito de "Transformar vidas desenvolvendo pessoas", nasce a Universidade Corporativa Gama. Importante destacar que este desenvolvimento de pessoas se vincula sempre às necessidades organizacionais, dentro do conceito de universidade corporativa pregada por Meister (1999).

Em conversa com a Analista de Educação da Empresa Gama, responsável pelas ações educacionais locais, nota-se que a Universidade Corporativa é vista pela organização como fator importante para a geração de vantagem competitiva, evolução nos negócios e aumento da sinergia organizacional, sendo, portanto, parte fundamental da gestão estratégica de recursos humanos.

Para a estruturação de seu modelo de Universidade Corporativa, a Empresa Gama apropria-se de conceitos que the favoreçam o alcance de sua missão e dos resultados esperados, e que the confiram credibilidade e seriedade ao processo instaurado, identificados como Fundamentos da Educação Corporativa (GAMA, 2013).

São fundamentos da Educação Corporativa adotados pela Empresa Gama: a Andragogia - didática de ensino voltada para aprendizagem de adultos, o Construtivismo - pressupondo que todos os seres humanos constroem sua concepção de realidade a partir de suas experiências pessoais e das inter-relações que estabelecem com o mundo, e a Educação Informal e o Autodesenvolvimento, ou seja, o "aprender fazendo + aprender compartilhando", sendo responsabilidade do sujeito a busca por sua capacitação e aperfeiçoamento. 
O modelo de aprendizagem adotado pela Universidade Gama é o $70: 20: 10$, ou seja: $70 \%$ da aprendizagem se dá pela experiência; $20 \%$ através da troca, seja com superiores, seja com seus pares; e $10 \%$ por programas formais de desenvolvimento (GAMA, 2013).

No ponto de vista da empresa, esse modelo reforça a responsabilidade do sujeito diante do seu processo de aprendizagem, incentivando-o a cultivar valores que são importantes para a organização, tais como pro-atividade, iniciativa, liderança e assumir responsabilidades, embasando o fundamento do autodesenvolvimento.

Tendo todas estas diretrizes delineadas, a Empresa Gama implanta seu sistema de Educação Corporativa, sempre alinhado com os valores, missão, visão e princípios da organização. Para esta organização, "o papel da educação na Gama é transformar conhecimentos em resultados para os negócios, com criatividade, tecnologias educacionais e colaboração" (GAMA, 2013).

Todo o processo de educação corporativa conta com o apoio e acompanhamento da Gerência de Recursos Humanos. Considerando a capilaridade da empresa, seja nacional e/ou internacionalmente, todos os processos são mapeados e descritos em procedimentos, que apontam os atores envolvidos no processo de educação da Empresa Gama e suas responsabilidades - Figura 3 - e cada um dos atores envolvidos neste processo assume sua responsabilidade - Quadro 1.

\section{Figura 3 - Atores no Processo de Educação Gama}

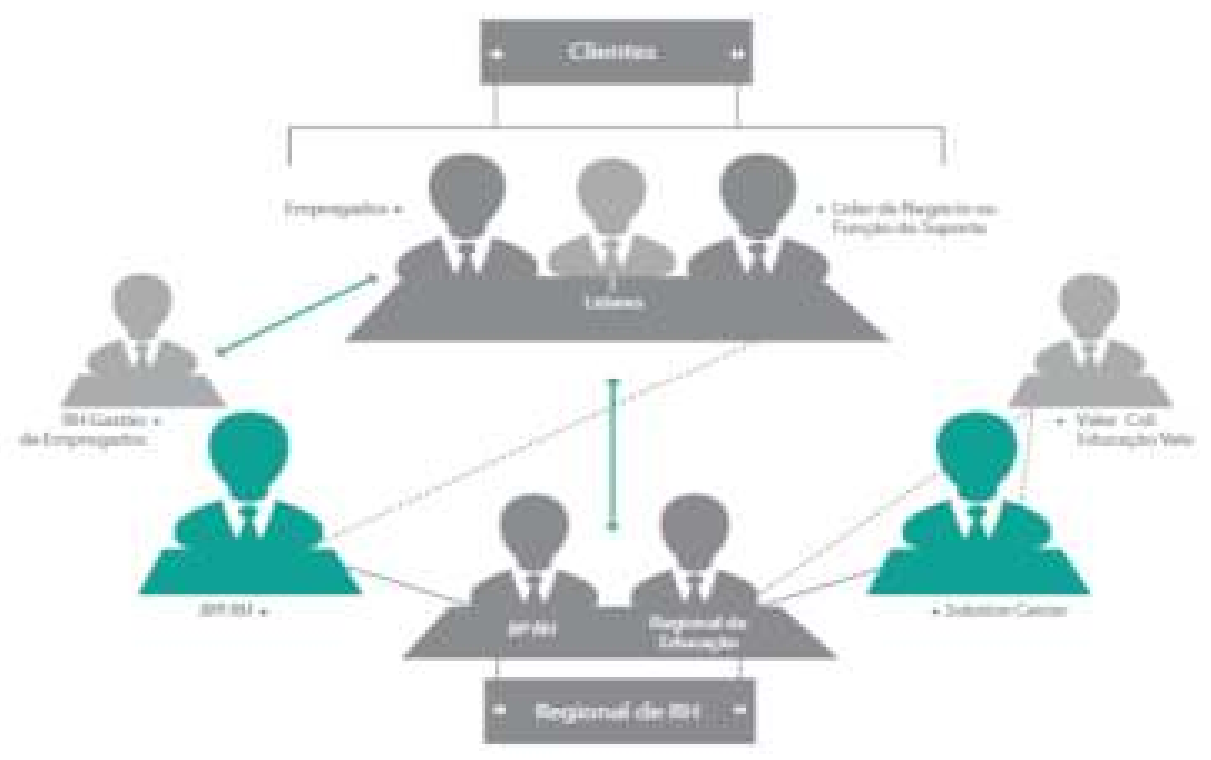

Fonte: GAMA, 2013 
Quadro 1 - Responsabilidades dos atores do processo de Educação

\begin{tabular}{|c|c|}
\hline ATOR & RESPONSABILIDADE \\
\hline Educação Corporativa & $\begin{array}{l}\text { Responsável pelas filosofias globais de educação; garante o alinhamento com } \\
\text { a missão, visão e valores da organização. Gerencia o sistema educacional, } \\
\text { seus programas, metas e resultados }\end{array}$ \\
\hline Solution Center & $\begin{array}{l}\text { Cuida do suporte às Equipes Regionais para implementação das ações } \\
\text { educacionais. Define e divulga diretrizes que apóiam o planejamento, } \\
\text { contratação, execução e acompanhamento das demandas de treinamento e } \\
\text { desenvolvimento. }\end{array}$ \\
\hline BPIs de RH & $\begin{array}{l}\text { Business Partners de RH vinculados à area estratégica da organização, são o } \\
\text { ponto de contato com os líderes de funções e negócios geograficamente } \\
\text { dispersos, sendo a fonte de informações para os Regionais de Educação e } \\
\text { Educação Corporativa. }\end{array}$ \\
\hline BP de RH & $\begin{array}{l}\text { Business Paurtner de RH: é ponto de contato com os clientes, os líderes da } \\
\text { organização em todos os níveis. Permite ter uma visão mais detalhada das } \\
\text { necessidades de cada área, sendo importante input de informações à } \\
\text { Universidade Corporativa. }\end{array}$ \\
\hline Regional de Educação & $\begin{array}{l}\text { Detém o conhecimento sobre o processo educacional local e sobre os modelos } \\
\text { aplicáveis àquela realidade. }\end{array}$ \\
\hline
\end{tabular}

Fonte: GAMA, 2013

Visando orientar a formação dos profissionais da Empresa Gama, dando visibilidade à formação das competências-chave de importância para o desempenho adequado frente a diversidade de tarefas, sem perder o foco no alinhamento estratégico da educação corporativa, a Universidade Gama constrói seu catálogo de treinamento específico para seus três modelos educacionais (GAMA, 2013) - Figura 4.

\section{Figura 4 - Modelos Educacionais}

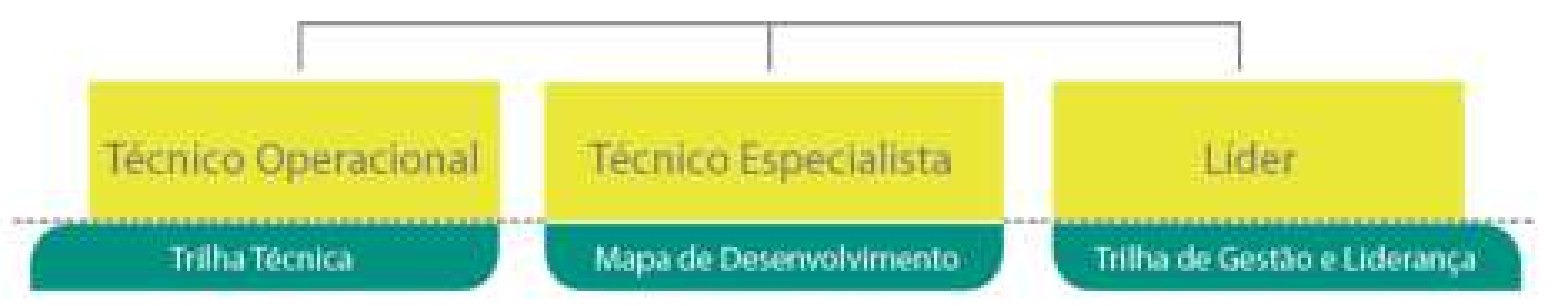

Fonte: GAMA 2013 
O objeto de estudo deste artigo é a Trilha de Gestão e Liderança, lançada em 2004 e que contempla profissionais brasileiros e em territórios estrangeiros da organização. Para garantir a credibilidade e efetividade deste programa, importantes parcerias com instituições educacionais em formação de liderança são estabelecidas.

Para melhor compreender a importância deste modelo educacional para a Empresa Gama, é importante considerar i) o papel do líder na Empresa Gama, que deve ter suas atitudes voltadas para as Pessoas, para os Resultados e para a Segurança e Saúde; ii) as bases conceituais adotadas pela Universidade Gama e o assumir do papel de protagonista de sua aprendizagem e ações - o desenvolvimento de um Líder Protagonista e iii) o desenvolvimento de competências de gestão e liderança que atendam não somente à organização, mas também às necessidades e aspirações pessoais dos profissionais envolvidos.

O programa de desenvolvimento "Trilha de Gestão e Liderança" conta com ações mandatórias àquelas obrigatórias e pré-requisitos para prosseguimento no programa, e ações opcionais, que agregam valor às práticas de gestão e liderança da organização. Dentre as ações mandatórias, cita-se o primeiro treinamento - Rito de Passagem - que demarca o início da atividade de gestão, apresentando ao novo líder a rotina e desafios com que se deparará em sua atividade laboral. Após este treinamento, há a oferta de ações que preparam o funcionário para as atividades da posição assumida, sob a temática de legislação trabalhista, gestão de equipes, comunicação e outros temas que se julgarem pertinentes e necessários aos gestores e líderes da organização (GAMA, 2013).

Para este artigo, foi possível realizar quatro entrevistas semi-estruturadas com Supervisores da Empresa Gama. Vale destacar que a adesão à pesquisa foi voluntária, sendo os únicos requisitos a atuação nos cargos de Supervisor/ Gerente e a participação na Trilha de Gestão e Liderança. Dentre os profissionais que aderiram, temos os apresentados no Quadro 2.

\section{Quadro 2 - Perfil dos Entrevistados}

\begin{tabular}{|l|c|c|c|c|}
\hline Entrevistado & $\begin{array}{c}\text { Tempo de } \\
\text { Empresa }\end{array}$ & Formação & Curso & Área de Atuação \\
\hline Supervisor A & 12 anos & Superior Completo & $\begin{array}{c}\text { Logística } \\
\text { Empresarial }\end{array}$ & Ferrovia \\
\hline Supervisor B & 03 anos & Pós-Graduação & $\begin{array}{c}\text { Engenharia de } \\
\text { Manutenção }\end{array}$ & Manutenção de Usinas \\
\hline Supervisor C & 16 anos & Superior Completo & Engenharia Elétrica & Ferrovia \\
\hline Supervisor D & 08 anos & Superior Completo & $\begin{array}{c}\text { Engenharia } \\
\text { Mecânica }\end{array}$ \\
\hline
\end{tabular}

Fonte: elaborado pelas autoras. 
A análise dos dados coletados em entrevistas segue as diretrizes estabelecidas por Bardin (2006), sendo definidas as categorias de análise apresentadas no Quadro 3.

\section{Quadro 3 - Categorias de Análise}

\begin{tabular}{|c|l|}
\hline $\begin{array}{c}\text { Reconhecimento da Empresa Gama e a } \\
\text { contribuição de seu trabalho }\end{array}$ & $\begin{array}{l}\text {. A organização pelo olhar do trabalhador } \\
\text {. A percepção do trabalhador sobre sai área de trabalho } \\
\text {. A comunicação corporativa }\end{array}$ \\
\hline $\begin{array}{c}\text { Reconhecimento e Construção das } \\
\text { Competências }\end{array}$ & $\begin{array}{l}\text {. O planejamento de ações para o alcance de metas e resultados } \\
\text { possíveis laçunas } \\
\text {. A formação da competência } \\
\text {. A formação do líder }\end{array}$ \\
\hline Competências 'na prática' & $\begin{array}{c}\text {. A mobilização do conhecimento para a ação e } \\
\text {. A 'mensuração' da competência }\end{array}$ \\
\hline
\end{tabular}

A seguir, serão apresentadas as análises dos dados com base nas categorias apresentadas.

Reconhecimento da Empresa Gama e a contribuição de seu trabalho

Compreender como se estabelece o relacionamento entre os Supervisores entrevistados e a Empresa Gama pode ser fator importante para o entendimento de como os treinamentos da Trilha de Gestão e Negócios são vivenciados pelos profissionais integrantes desta pesquisa e, grande parte desta percepção foi capturada pela pesquisadora por meio da observação, pela interpretação de falas e posturas adotadas durante realização das entrevistas.

O Supervisor A e o Supervisor D foram profissionais formados pela Empresa Gama. Tendo o Supervisor A vindo de um curso técnico, e o Supervisor D iniciando na empresa como estagiário, ambos tiveram na Empresa Gama a oportunidade de seu primeiro emprego. Aproveitaram esta oportunidade e conseguiram 'fazer carreira' na organização. Essa característica confere a eles as mesmas posturas e expressões ao referirem-se à Empresa Gama, e a importância de terem atuado em diferentes unidades operativas e de conhecer diversas áreas da empresa ao longo de sua formação profissional. O Supervisor A, que teve oportunidade de trabalhar em unidades operativas no estado de Minas Gerais, acredita que

[e]ssa passagem minha ao longo desses anos, vai pra cá, vem prá lá, passando por pontos diferentes isso agregou a ter conhecimento pra hoje operar e ser um gestor de todo um centro de controle que é um negócio mais complexo, que a gente precisa entender o funcionamento como um todo. Tem toda parte de gestão, lógico, que não tem nada a ver com o operacional, mas, entendimento operacional facilita muito a tomada de decisão, o que a gente faz no dia a dia voltado a gestão (SUPERVISOR A) 
Já o Supervisor $D$, que iniciou como estagiário, foi contratado como trainee, atuou por um ano também no estado de Minas Gerais, retornou a unidade de Vitória/ES e atualmente supervisiona a equipe em que foi estagiário, identifica seu trabalho como "crucial para a ferrovia" (SUPERVISOR D):

Se eu tirar hoje a equipe de confiabilidade, o negócio roda muito bem nos próximos seis meses. Depois de seis meses, quem é que previu o que ia acontecer agora? Quem é que evitou preventivamente algumas coisas que não quebrariam hoje, se não fosse a confiabilidade pela responsabilidade que ela tem no processo? (...) Essa é a importância da equipe de confiabilidade para a empresa Gama (SUPERVISOR D).

Nota-se um relacionamento que vai além da simples relação de trabalho formal entre empregado e empregador, que demonstra certa afetividade para com a Empresa Gama.

O relacionamento entre o Supervisor B e a Empresa Gama é o mais recente dentre os supervisores entrevistados. Por ter vindo de uma empresa da área de siderurgia, onde formou-se profissionalmente, apresenta uma visão mais crítica quanto as práticas da Empresa Gama, e acredita que pode contribuir para melhorá-las em sua área de atuação. Há uma comparação inevitável entre a empresa anterior e a Empresa Gama

A cultura da própria Gama é diferente, em relação à formação profissional. O que eu senti maior diferença entre as duas empresas foi a gama de treinamentos técnicos. Agora que estamos começando um trabalho de treinamento técnico, desenvolvimento de pessoal. E eu vim de uma empresa que já tinha isso na cultura dela. Essa foi a principal diferença. Você chegar e entrevistar um executante e ele falar: eu aprendi por que me ensinaram (...) o aprendizado aqui vem de empregado para empregado (SUPERVISOR B).

Percebe-se que, para o Supervisor $\mathrm{C}$, esse relacionamento se apresenta com um senso de oportunidade, tanto pessoal quanto profissional, muito marcante. Embora já atue na empresa há catorze anos, este Supervisor equilibra a relação de afeto e o profissionalismo, apontando com muita naturalidade as evoluções e as questões que considera críticas da empresa, como no comentário a seguir:

Eu acho até legal esse bate papo nosso sobre competência, como a empresa está investindo na capacitação da liderança, por que neste primeiro momento que eu fui Supervisor a gente não tinha isso no primeiro momento. Eu fiquei supervisor durante um ano e não tive tantos treinamentos quanto eu tive nestes últimos anos (SUPERVISOR C).

Embora esta relação entre empresa e empregado tenha sido construída sob pilares e valores diferentes, fica claro que os supervisores entrevistados possuem o sentimento de valia por seu trabalho: demonstram saber o que a organização espera de sua conduta profissional e entregas a serem realizadas e, em contrapartida, tem a clareza do valor e da importância de seu trabalho para a organização, e sentem-se "peças" fundamentais para a continuidade de seu sucesso. 
Reconhecimento e Construção das Competências

Para melhor compreensão do conceito de competências para a Empresa Gama, é válida a retomada dos estudos de Amaro (2005), e sua abordagem sobre a introdução da noção de competências na Empresa Gama. Em seus estudos, este autor apura que foi a partir do primeiro planejamento estratégico da Empresa Gama, referente ao período de 1989-2000, cujo legado foi o investimento em novas ferramentas e tecnologias de gestão. Dentre estas tecnologias, o autor destaca o fortalecimento de processos voltados para a gestão da qualidade, que exigiram a intensificação de treinamentos para todos os funcionários da empresa.

A privatização da Empresa Gama traz impactos diretos ao grupo de profissionais responsáveis por sua gestão estratégica, sendo esperadas mudanças e substituições, seja por demanda da empresa, seja pela adesão ao Programa de Demissão Incentivada. Faz-se então necessária a formação e preparação de novos gestores para os novos desafios da organização.

Em 1992 é lançado o "Plano de Desenvolvimento, Carreira e Sucessão - PDCS", com o objetivo de ser uma ferramenta de apoio para a identificação de carências e experiências de seus funcionários. A noção de competência é inserida neste plano no ano seguinte à privatização da organização (AMARO, 2005).

Amaro (2005) destaca que, naquele momento, o conceito de competências adotado pela empresa Empresa Gama aproxima-se do conceito americano de competência, apresentada como a mobilização dos recursos do indivíduo para atingir um desempenho de excelência, sendo ele:

[u]m conjunto de atributos ligados à personalidade, conhecimentos, habilidades, valores, experiências e que, articulados, mostram o âmbito possível do desempenho. Competências são avaliadas pelo histórico e realizações (AMARO, 2005, p. 86).

Atualmente, o conceito de competência da Empresa Gama adere-se aos programas de treinamento oferecidos por sua Universidade Corporativa, conforme o grupo de profissionais a serem atendidos. Ou seja, os profissionais de nível técnico, que aderem aos treinamentos oferecidos pela Trilha Técnica, têm como competência

[a] capacidade de gerar resultados observáveis, necessários ao alcance dos objetivos de negócios e culturais. É um conceito pelo qual são definidas as atitudes (querer fazer), as habilidades (poder fazer) e os conhecimentos (saber fazer) necessários para alcançar resultados diferenciados, ou seja, o conjunto de qualificações desejáveis para atuar nos processos da organização (GAMA, 2013, p. 72).

Já para os profissionais de nível superior, embora sutil, o conceito de competência apresenta diferenças em seu foco, sendo ele

[c]onjunto de qualificações desejáveis para atuar no processo da organização. É o conceito pelo qual são definidas as atitudes (querer fazer), as habilidades (poder fazer) e os conhecimentos (saber fazer) necessários para alcançar resultados diferenciados e relacionados ao objetivo dos negócios (GAMA, 2013, p.87). 
Nota-se que há ainda uma forte aproximação destes conceitos à noção americana de competência. Contudo, com o aumento da complexidade da gestão de pessoas na Empresa Gama, cada nível de atuação exibe seu próprio conceito de competências: seja ele voltado para os resultados observáveis (técnicooperacional), seja ele atrelado aos objetivos do negócio (nível superior).

Durante as entrevistas realizadas, este conceito surge arraigado em todos os supervisores entrevistados, associados ao alcance de resultados e questões de saúde e segurança do trabalhador.

Retomando o reconhecimento e a construção das competências, em uma organização que prioriza o modelo de 70:20:10 de aprendizagem, não é surpresa que os treinamentos on the job, ou seja, o aprender fazendo, orientado por profissional mais experiente, seja a prática mais comum entre os profissionais da Empresa Gama.

A Trilha de Gestão e Liderança, objeto de estudo desta pesquisa, é uma exceção a esta tendência da empresa, oferecendo em seu Programa treinamentos prioritariamente presenciais e vivenciais.

Para o Supervisor D,

[n]a verdade o que é o grande lance destes treinamentos que a Empresa Gama prepara pra gente: pega técnicas desenvolvidas no ambiente corporativo que existe fora da empresa e faz uma analogia prática com o que realmente acontece. E o grande objetivo é elucidar situações onde o líder precisa se comporta, como o líder deve lidar, exemplo de feedback, desenvolvimento de carreira e sucessão (...) Pega fatos que acontecem realmente e a gente estuda, analisa. É trazer para o ambiente teórico, a sala de aula, a prática de como a gente deve lidar com situações adversas (SUPERVISOR D).

O primeiro treinamento da Trilha de Gestão e Liderança, mandatário para que todos os demais ocorram, é o conhecido "Rito de Passagem". Este treinamento tem por objetivo confrontar o novo líder com a realidade das atividades de gestão que assumirá dali por diante. Segundo o Supervisor C,

[é] o momento... é muito simbólico. Aquele é o momento que deixa muito claro para você: "você aceitou sair de uma carreira técnica, pra carreira de gestão. Você parou de cuidar de equipamento para cuidar de gente, pessoa humana. É isso mesmo que você quer, está preparado pra isso? E começa a explicar pra gente qual a mudança na carreira de técnico para gestão" (SUPERVISOR C)

Contudo, nota-se que todos os entrevistados participaram deste treinamento após estarem desenvolvendo as atividades de Supervisão:

Eu fiz o rito até alguns meses depois que eu já tinha assumido a função, por questão de agenda e tal. Mas ali o cara decidiu: opa! Eu estou de um lado que realmente me demanda algumas coisas, que é isso mesmo que eu estou. Acho que geralmente quem chega no rito, quem passa por essa condição, já sabe desse caminho. Mas eu acho que a grande marca do rito é isso: que lá ele vai entrando ponto a ponto, de situações que vão acontecer com o gestor daqui pra frente e que são situações que não é mais de ninguém, é do gestor e ele que vai ter que atuar em relação aquilo (SUPERVISOR A).

Outro aspecto importante dos treinamentos que integram a Trilha de Gestão e Liderança é sua característica de uma formação subjetiva, de difícil mensuração, própria dos treinamentos comportamentais. Embora haja pesquisas desenvolvidas que se empenham na validação de escalas para mensuração da aprendizagem no trabalho (BRANDÃO e BORGES-ANDRADE, 2011), as mudanças advindas de 
treinamentos comportamentais referem-se muito mais a uma percepção do que a uma aferição, daí seu caráter subjetivo.

Para o Supervisor D, a abordagem comportamental dos treinamentos apóia sua prática profissional, e é na prática que ele deve ser acompanhado e avaliado. O Supervisor $\mathrm{C}$, quando questionado sobre a importância e influência dos treinamentos comportamentais, diz que "de $80 \%$ a 85\% (das vezes) eu dou uma pensada, eu moldo o meu comportamento, as minhas atitudes, por causa dos treinamentos comportamentais. Ajuda demais!".

Observa-se, então, uma concordância entre os supervisores entrevistados de que há influência dos programas de educação corporativa em sua rotina e práticas de gestão. Mas, qual será a importância desta influência na formação das competências?

\section{Competências 'na prática'}

Todos os Supervisores entrevistados trazem a lembrança de situações cotidianas em que, diante de um evento, houve a necessidade de agir em concordância com os conhecimentos adquiridos, convergindo para idéia de que "a competência é um entendimento prático de situações que se apóia em conhecimentos adquiridos e as transforma na medida em que aumenta a diversidade das situações" (ZARIFIAN, 2001, p. 73).

Para o Supervisor D, sua participação nos treinamentos da Trilha de Gestão e Liderança provocou uma mudança em sua visão sobre as necessidades de sua equipe:

[p]ra mim o grande ponto gerado neste treinamento foi o seguinte:hoje eu estou com uma estrutura de confiabilidade (...), são os caras mais questionadores, que de formação profissional, as pessoas já estão em um patamar bem acima de outras equipes. E eu quando vim para a Confiabilidade eu achei que vinha para uma equipe mais sênior, equipe mais pensante, mais questionadora e eu tinha a falsa impressão de que essas pessoas não precisariam ser desenvolvidas. E eu fui percebendo que não. E foi esse treinamento "Liderando pessoas" foi onde eu tive esse insight: preciso mapear as pessoas, preciso desenvolvê-las (SUPERVISOR D).

O Supervisor C, que prioriza e valoriza os treinamentos comportamentais, comenta que a maior mudança advinda dos treinamentos da Trilha de Gestão e Liderança foi em relação a sua postura e atitudes diante da equipe: a percepção das diferenças e saber a melhor forma de lidar com elas dentro da equipe, a habilidade em delegar tarefas. Segundo ele, "supondo que eu tenho o orçamento apertado este ano, eu tenho essa gama de treinamentos, eu focaria mais na parte comportamental" (SUPERVISOR C). Para este Supervisor, a contribuição dos treinamentos da Trilha de Gestão e Liderança para o desenvolvimento de competências esperadas pela organização representam $40 \%$, sendo $60 \%$ vinculados a prática e treinamentos técnicos.

O Supervisor B, por já ter tido experiência em cargos de liderança em outras organizações, aponta que a grande contribuição da Trilha de Gestão e Liderança foi a reciclagem do conhecimento. A aplicação deste, para ele, já era parte de sua rotina laboral. Cita, dentre os treinamentos de destaque, o de Rotinas Trabalhistas, área específica, que não é de seu conhecimento técnico, e que difere da antiga empresa em que trabalhava. Outro treinamento que ganha destaque por este Supervisor é o de Práticas de Feedback, que o capacita para, dentro da nova cultura organizacional, comunicar aos seus subordinados a avaliação de seu 
desempenho diante de uma dada situação. Ele acredita que estas ferramentas agregam a sua prática e facilitam o gerenciamento da equipe. Quando solicitado sobre uma situação em que pôde utilizar tais conhecimentos, cita

[e]u lembrei do treinamento quando o empregado me relatou que estava precisando tomar um remédio controlado por que ele estava com dificuldade de concentração na faculdade. E aí ele precisou tomar um remédio tarja preta. E aí eu lembrei, dos treinamentos, que todo medicamento pode influenciar na conduta, nas ações do empregado. Daí eu lembrei e encaminhei este empregado ao posto médico. Diante da entrevista, a médica restringiu ele em algumas atividades (SUPERVISOR B).

Já para o Supervisor A, a importância de desenvolvimento de competências gerencias veio na prática:

Tem um fato, eu tinha pouco tempo de gestor, quando a gente entrou naquela crise de 2008. A empresa passou por momentos difíceis, teve uma estratégia adotada na época e a gente teve vários desligamentos. E era aquele desligamento que você não tinha um histórico pra falar. Você sabia o motivo por que a pessoa estava saindo: você entrava na sala e tinha que reduzi a quantidade de pessoas e você escolhia ali, em ordem de prioridade, aquele que tinha o menor rendimento comparado aos demais. Tinham pessoas que tinha entrado na empresa a dois, três, cinco meses. E eu tive que fazer um desligamento de um desses empregados, e eu não tive o cuidado de olhar a data de desligamento e se tinha alguma coincidência que poderia se afetar. No momento do desligamento eu recebi a resposta: 'Pô, que presente de aniversário'. (SUPERVISOR A)

Este Supervisor conta que levou esta experiência vivenciada para o ambiente de treinamento, compartilhando-a com os colegas e reforçando a idéia do aprendizado pela troca de experiências.

Os Supervisores sugerem que os treinamentos da Trilha de Gestão ocorram fora do ambiente de trabalho, preferencialmente que o Supervisor não tenha comunicação com o exterior durante o treinamento. Para eles, a prática de, por exemplo, não permitir a entrada em ambientes de treinamento portando celulares ou aparelhos eletrônicos é fundamental para garantir a concentração e o aprendizado, e deve

Para finalizar, fica o relato do Supervisor A: "O Programa é bacana. Programa que busca agregar conhecimento ao gestor".

\section{CONSIDERAÇÕES FINAIS}

Este trabalho buscou descrever o programa de desenvolvimento "Trilha de Gestão e Liderança", oferecido pela Universidade Corporativa Gama, e compreender suas possíveis relações com o desenvolvimento as competências profissionais esperadas pela Organização. Para tanto, trabalhos e contribuições teóricas sobre o tema Competência (FLEURY E FLEURY, 2001; LE BOTERF, 2003; ZARIFIAN, 2001, 2003) e sobre o tema Educação Corporativa (EBOLI, 1999, 2002, 2004; MEISTER, 1999) foram importantes norteadores.

Constata-se que a Universidade Corporativa Gama desempenha importante papel na formação dos profissionais da Empresa Gama, oferecendo ambientes e ações propícias ao desenvolvimento e à aprendizagem, além de um cardápio de mais de 6.000 mil treinamentos, disponíveis a todos os profissionais, de todos os níveis hierárquicos da organização, e acessível por meio de seu Sistema de Gerenciamento, o GES. 
Contudo, embora os profissionais entrevistados reconheçam, valorizem e participem de um volume considerável de treinamentos ao longo de seu período na Empresa, quando se fala especificamente da Trilha de Gestão e Liderança, alguns pontos devem ser observados com atenção.

Há que se apontar uma importante lacuna neste processo, aspecto percebido durante a imersão no campo: a definição de como este 'caminhar' na Trilha se dará no tempo. Ou seja: definir o momento e a periodicidade para que os treinamentos aconteçam. Outro ponto a ser considerado quando se trata de definição da periodicidade para a realização dos treinamentos propostos pela Trilha refere-se à continuidade da formação e do desenvolvimento do profissional. Os longos espaços de tempo que acontecem entre um treinamento e outro prejudicam a percepção do profissional quanto ao cumprimento do Programa e, por conseqüência, quanto à percepção de seus resultados e impactos para o desenvolvimento das competências esperadas. Daí a dificuldade dos entrevistados em reconhecer os treinamentos da Trilha de Gestão e Liderança, rememorando-os a partir da citação do treinamento de Rito de Passagem. Outro aspecto a ser observado é que, ao longo destes intervalos, os treinamentos propostos pela Trilha de Gestão e Liderança misturam-se a enorme cartela de treinamentos ofertados e ao volume de treinamentos diversificados à que os profissionais se submetem, diluindo-se sua importância.

Essa dificuldade de encadeamento e fluidez na execução dos treinamentos associada à ferramenta de avaliação, que se restringe a capturar a percepção sobre os treinamentos no momento imediato de seu término - Avaliação de Reação, apontam para uma dificuldade de monitoramento dos resultados do Programa Trilha de Gestão e Liderança por parte da equipe de Educação Corporativa. Esta dificuldade é agravada pela característica dos treinamentos propostos por este Programa, que dão foco aos aspectos comportamentais e competências de difícil mensuração, tais como: Liderança, Desenvolvimento de Pessoas e Inteligência Organizacional, por exemplo.

Retomando nosso problema de pesquisa, pode-se dizer que o Programa Trilha de Gestão e Liderança, oferecido pela Universidade Corporativa Gama, é bem-sucedido em seu propósito de formar as competências esperadas pela Empresa Gama.

Mas, vale destacar que não é o único responsável por esta formação. O acompanhamento cotidiano pelas Gerências, as trocas de informações entre os profissionais mais experientes, o autodesenvolvimento, a autonomia na tomada de decisão, estes sim são considerados fundamentais para o desenvolvimento das competências esperadas pela Organização. Os espaços dos treinamentos formais, como os propostos pela Trilha de Gestão e Liderança, passam a ser atrativos e motivadores não pelo conteúdo a ser abordado, mas sim pela troca de experiências que ali ocorre. Essa interação é apontada pelos entrevistados como uma gratificante oportunidade de aprendizado, considerando que há uma identificação entre os participantes e as situações que por eles são vivenciadas.

Há sempre um risco na retomada de temas já bastante debatidos pela academia, como Competências e Educação Corporativa. Espera-se com este trabalho ter contribuído com os estudos já em andamento, apresentando informações de uma realidade atual, e reafirmando a necessidade de estudos neste campo. Sugere-se para pesquisas futuras a aproximação destas duas temáticas com programas de Carreira e Sucessão e/ou Remuneração, importantes tecnologias de gestão utilizadas pelas organizações. 


\section{REFERÊNCIAS}

ALPERSTEDT, C. Universidades Corporativas: discussão e proposta de uma definição. Revista de Administração Contemporânea, v.5, n.3, set-dez, 2001.

AMARO, R. A. As metamorfoses da qualificação diante da introdução da noção de competência nos espaços organizacionais: o estudo em uma grande empresa de mineração e logística. 2005. 143f. Dissertação (Mestrado em Administração). Programa de Pós-Graduação em Administração. Universidade Federal do Espírito Santo, Vitória, 2005.

BARDIN, L. Análise de conteúdo. Lisboa: Edições 70, 2006.

BOLTANSKI, L.; CHIAPELLO, E. O Novo Espírito do Capitalismo. São Paulo: Editora WMF Martins Fontes, 2009.

BRANDÃO, G. R. Gestão de pessoas e a universidade corporativa: dois lados da mesma moeda?. RAE - Revista de Administração Eletrônica, v.46, n.02, abr-jun, 2006.

BRANDÃO, H. P.; BORGES-ANDRADE, J. E. Desenvolvimento e Validação de uma Escala de Estratégias de Aprendizagem no Trabalho. Psicologia: Reflexão e Crítica, v.24, n.03, 2011.

BRAVEMAN, H. Trabalho e Capital Monopolista: a degradação do trabalho no séc. XX. LTC Editora, $1^{\text {a }}$ Ed., 1974.

CASTELLS, M. A Sociedade em Rede: a era da informação. Economia, Sociedade e Cultura, v.1, São Paulo: Terra e Paz, 1999.

DUTRA, J. S. Competências: conceitos e instrumentos para a gestão de pessoas na empresa moderna. São Paulo: Atlas, 2010.

EBOLI, M. Educação Corporativa no Brasil: Mitos e Verdades. São Paulo: Editora Gente, 2004.

EBOLI, M. Universidade Corporativa: ameaça ou oportunidade para as escolas tradicionais de administração? Revista de Administração, v.34, n.4, p.56-64, out-dez, 1999.

EBOLI, M. O desenvolvimento das pessoas e a educação corporativa. In: FLEURY, M. T. L. (Org.) As pessoas na Organização. São Paulo: Editora Gente, 2002.

FARIA, J. H. Economia política do poder: uma crítica da teoria geral da administração. Curitiba: Juruá, 2008

FARIA, J. H. Gestão Participativa: relações de poder e de trabalho nas organizações. São Paulo: Atlas, 2009.

FLEURY, M. T. L.; FLEURY, A. Construindo o conceito de competência. Revista de Administração Contemporânea. Ed. Especial, 2001. p. 183-196.

FLICK, U. Uma introdução à pesquisa qualitativa. Porto Alegre: Bookman, 2004.

FRANCO, M. L. P. B. Análise de conteúdo. Brasília: Editora Plano, 2003.

GAMA. Processo de Educação na Gama. 2013.

GASKELL, G. Entrevistas individuais e grupais. In.: BAUER, M. W.; GASKELL, G. Pesquisa qualitative com texto, imagem e som. Rio de Janeiro: Vozes, 2002.

HARVEY, D. A condição pós-moderna. São Paulo: Edições Loyola, 1992.

LE BOTERF, G. Desenvolvendo a competência dos profissionais. Porto Alegre: Artmed, 2003.

MEISTER, J. Educação Corporativa. São Paulo: Makron Books, 1999.

PILATI, R.; PORTO, J. B.; SILVINO, A. M. D. Educação Corporativa e Desempenho Organizacional: há alguma relação? RAE Eletrônica. v.8, n.2, jul-dez, 2009.

SALERNO, M. S. Projeto de organizações integradas e flexíveis: processos, grupos e gestão democrática via espaços de comunicação-negociação. São Paulo: Atlas, 1999.

TAKEUCHI, H; NONAKA, I. Gestão do conhecimento. Porto Alegre: Bookman, 2008.

WEBER, M. Burocracia. In.: WEBER, M. Ensaios de Sociologia. Rio de Janeiro: Zahar, 1982. p. $229-282$.

ZARIFIAN, P. Objetivo Competência: por uma nova lógica. São Paulo: Atlas, 2001.

ZARIFIAN, P. O Modelo da Competência: trajetória histórica, desafios atuais e propostas. São Paulo: Editora SENAC, 2003. 